\title{
INTERSECCIONALIDADES E A PROMOÇÃO DA SAÚDE NOS GRUPOS REFLEXIVOS E DE APOIO AO LUTO
}

\author{
INTERSECTIONALITY AND TO HEALTH PROMOTION IN \\ REFLECTIVE AND BEREAVEMENT GROUPS
}

\begin{abstract}
Ivania Jann Luna ${ }^{1}$
Mateus Alves Silva ${ }^{2}$

\section{RESUMO}

Este artigo consiste em um relato de experiência sobre os grupos reflexivos e de apoio ao luto facilitados no contexto de um serviço escola de Psicologia de uma universidade pública, considerando também o uso das tecnologias da informação e da comunicação durante o período da pandemia pelo novo coronavírus Sars-coV-2. Apresentam-se os aspectos teóricos, procedimentos e resultados dos grupos e que são discutidos à luz dos seguintes princípios: interseccionalidade, direito ao luto público e coletivo, processo de luto, ética relacional e princípios terapêuticos grupais. Foram realizados seis grupos e obteve-se um total de cinquenta pessoas participando de reflexões sobre as necessidades de apoio, modos de expressão do luto, impactos do luto na saúde mental e na família, vivências interseccionais no luto e modos de cuidar e conviver com as perdas. Os desafios da promoção à saúde no luto em contexto grupal consistem na coconstrução de narrativas bem como espaços de fala e escuta, empatia, sociabilidade e confiança levando em conta as interseccionalidades presentes nos grupos.
\end{abstract}

Palavras-chaves: Luto; Grupos de Apoio; Promoção da Saúde; Interseccionalidades.

\begin{abstract}
This article consists of an experience report on the reflective and bereavement support groups that were facilitated in the context of a Psychology school service at a public university, also considering the information and communication technologies during the period of pandemic by the new coronavirus Sars-coV-2. The theoretical aspect, procedures and results of the groups are presented and discussed in the light of intersectionality, the right to public mourning, the mourning process, relational ethics and group therapeutic principles. A total of fifty people were participating in reflections around the needs and expression of the mourning, the impacts of mourning on mental health and the family, the intersectional experiences, and the way to care for and living the loss. The challenges of health promotion in mourning in a group context consist of cobuilding narratives, as well as spaces for speech and listening, empathy, sociability and trust taking into account the intersectionality present.
\end{abstract}

Keywords: Mourning; Support Groups; Health Promotion; Intersectionality.

\footnotetext{
${ }^{1}$ Atualmente é Professora Adjunta do Departamento de Psicologia da Universidade Federal de Santa Catarina. Pós-doutora em Psicologia Clínica pela Pontifícia Universidade Católica de São Paulo (PUC/SP). Doutora em Psicologia pela Universidade Federal de Santa Catarina. e-mail: ivania.j.1@ufsc.br

${ }^{2}$ Bacharel em Psicologia pela Universidade Federal de Santa Catarina. e-mail: mateuspsico2015@gmail.com
} 


\section{Revista (O) \\ Debates Insubmissos}

\section{INTRODUÇÃO}

Estudos sobre a morte, os processos de morrer, perdas e luto existem desde a Antiguidade, construindo e sendo construídos pelas estruturas de significados existentes ao longo das sociedades. Especialmente a área de estudos denominada de "Educação para a morte" apresenta as mudanças históricas e sociais na oferta de cuidados às pessoas gravemente enfermas ou enlutadas, bem como, destaca as interlocuções necessárias ao Estado Brasileiro quanto à garantia de direitos ao cuidado à morte, ao processo de morrer e ao luto (KOVÁCS, 2008; MORAES; STOLZ, 2013).

Assim como o direito inviolável à vida está vigente no Art. $5^{\circ}$ da Constituição Federal de 1988, o direito a um tratamento digno e humanizado diante do morrer deve ser garantido. Nesse sentido, em 31 de outubro de 2018, foi expedida a resolução de $n^{\circ} 41$, na qual se define que a modalidade denominada Cuidados Paliativos deverá contar com o trabalho em equipe multiprofissional e interdisciplinar acerca das necessidades dos pacientes e de seus familiares, incluindo o aconselhamento ao luto em qualquer ponto da rede de atenção à saúde.

Paralelamente a essa questão, observam-se discussões em relação à ampliação da oferta de ações de promoção à saúde, acolhimento e suporte social para enlutados na atenção à saúde comunitária e em instituições públicas (SANTOS, 2017). Nesse sentido, salienta-se a importância da temática do cuidado ao luto e da promoção à saúde como um dos focos que subsidiou a construção do projeto de extensão "Intervenções no luto: acolhimento e suporte psicológico" e que é desenvolvido, desde 2017, pelos autores do presente artigo e conta com a participação de extensionistas de graduação e pós-graduação em Psicologia de uma Universidade Pública.

Neste projeto, a promoção à saúde é entendida como o fortalecimento dos sujeitos enlutados pela coconstrução de recursos de enfrentamento e criação de mais espaços para o acolhimento, sendo que isso envolve o amparo do coletivo e redes sociais de apoio e acolhimentos que façam sentido para o enlutado na construção de significados de vida e de morte (SANTOS, 2006; LUNA, 2020). Para tanto, no escopo do referido projeto de extensão, realizam-se ações de suporte psicológico no luto - psicoeducativas e terapêuticas -, 
especialmente, os grupos reflexivos e de apoio ao luto que estão implicados com a discussão da promoção da saúde e de ambientes saudáveis (BUSS, 2003), do direito ao luto público (BUTLER, 2018), da ética relacional (GERGEN, 2016) e dos princípios terapêuticos grupais (YALOM; LESZCZ, 2006).

Tendo em vista os aspectos abordados até o momento, este artigo apresenta o relato de experiência sobre os grupos reflexivos e de apoio ao luto que foram facilitados no período de outubro de 2017 a dezembro de 2020. Para tanto, caracteriza-se os princípios do suporte psicológico grupal ao luto e o atendimento psicológico online, os procedimentos e os resultados obtidos nos grupos reflexivos e de apoio ao luto. Finaliza-se este relato com discussões sobre os desafios à promoção da saúde no luto que estiveram presentes nos grupos realizados.

\section{SUPORTE PSICOLÓGICO GRUPAL AO LUTO E O ATENDIMENTO ONLINE}

O luto é uma vivência esperada frente à perda de uma pessoa ou objeto significativo. $\mathrm{Na}$ atualidade, o protagonismo do enlutado envolve acionar recursos simbólicos para a elaboração de um luto, como os rituais de morte da cultura, ou ainda, por meio do acesso aos serviços de apoio ao luto. De acordo com Santos (2017), as pessoas enlutadas se beneficiam de ações de suporte psicológico no contexto imediato pós-perda, e que visam interferir no modo como elas vivenciam a qualidade da comunicação e apoio social às vivências agudas de luto. A busca de pais enlutados por grupos de apoio ao luto parental é um exemplo. Também há muitas pessoas que procuram os grupos de pósvenção e de apoio ao luto por suicídio ou ainda outros enlutados por diversas perdas buscam apoio em grupos de luto.

Por sua vez, há diferentes modalidades de grupos de apoio ao luto a depender dos tipos de intervenções realizadas, seu local de realização ou objetivo. São exemplos, grupos de mútua ajuda, grupos terapêuticos de luto e os grupos psicoterápicos de luto. Nos grupos de mútua ajuda e terapêuticos são realizadas tanto intervenções primárias quanto secundárias visando fomentar recursos comunitários e de psicoeducação, como a partilha de situações comuns, a diminuição de isolamento social, bem como a obtenção de informações sobre o 


\section{Revista
Debates Insubmissos}

processo de luto (REBELO, 2005). Ademais, a perspectiva da promoção à saúde ao luto também está presente na medida em que se busca transcender a visão de que as pessoas enlutadas autoavaliem ou compreendam as suas reações ou conflitos com a perda a partir do referencial teórico biomédico, medicalizante ou ainda produzidos em um contexto cultural e social diferente do vivenciado pela pessoa em luto (LUNA, 2020). E como local de realização destes tipos de grupos estão as igrejas (SOARES et al, 2020), as unidades básicas de saúde (SOUZA e SANTOS, 2016) e as organizações não governamentais como exemplificam Davel e Silva (2014) e Scavacini, Cornejo e Cescon (2019).

Por sua vez, somente os grupos terapêuticos e psicoterápicos de luto exigem de seus coordenadores a formação e o domínio de recursos da escuta ativa. No que tange os grupos psicoterapêuticos, as intervenções são terciárias e têm como objetivo o tratamento de reações complicadas de luto a partir de suporte psicológico oferecido na unidade de terapia intensiva neonatal (RUBIO et al, 2016), no ambulatório geral (PASCOAL, 2012; GUILLÉN, MONTAÑO; GORDILLO, 2015) e na emergência geral (SOUZA, MOURA e CORRÊA, 2009). Neste tipo de grupo é importante que os enlutados compreendam as suas reações ou conflitos com a perda a partir do conceito de transtorno do luto complexo e persistente, categoria clínica que foi incluída como condição de pesquisa no Diagnostic Statistical Manual of Mental Disorders - Fifty. (PRIGERSON, VANDERWERKER; MACIEJEWSKI, 2008).

O grupo reflexivo e de apoio ao luto (Gral) tem como foco a mútua ajuda com finalidades terapêuticas e pode ser considerado também um grupo de promoção à saúde. Neste sentido, o principal objetivo é promover a autoria e o protagonismo grupal das pessoas a partir de suas vivências individuais e coletivas de luto. Isto é alcançado a partir do estímulo à narração de histórias pessoais sobre a perda vivida; da construção de empatia em torno das necessidades de enlutamento de cada participante e das interseccionalidades envolvidas; bem como da sociabilidade no compartilhamento de recursos de enfrentamento no luto (LUNA, 2020). 
No período de outubro de 2017 a julho de 2019 facilitou-se cinco grupos, sendo que em agosto de 2020 a oferta do grupo foi retomada e precisou ser ampliada para o formato virtual, levando em consideração as medidas de segurança propostas pela World Health Organization (2021), cuja recomendação foi, entre outras, o distanciamento físico para impedir a transmissão do novo coronavírus Sars-coV-2. Por sua vez, a pandemia reforçou a importância da realização de um Gral exclusivamente voltado para pessoas enlutadas pela Covid-19, na medida em que foi necessário atentar para as especificidades do processo de luto destas pessoas que incluem as múltiplas perdas, o sentimento de culpa pela possibilidade da pessoa ter sido agente transmissor ao ente querido, a impossibilidade de estarem presentes junto ao ente querido no período que antecedeu a sua morte, as limitações dos rituais de despedida, a obrigatoriedade do caixão fechado e a redução do número de pessoas nos funerais (DANTAS et al, 2020; SCHMIDT et al, 2020). Ademais, a noção de luto coletivo esteve presente no Gral realizado no contexto online, uma vez que se ampliou a oferta deste grupo para além da cidade de referência em que se situa o referido projeto de extensão, a cidade de Florianópolis.

Observa-se que os atendimentos psicológicos realizados em formato virtual através das Tecnologias da Informação e da Comunicação (TICs) não são recentes na profissão de psicólogo, contudo foram pouco debatidos antes do início da pandemia do novo coronavírus Sars-coV-2. Destaca-se que a operacionalização das TICs se estruturou pela Resolução do Conselho Federal de Psicologia de no 012/2005 e, por isso, regulamentou os atendimentos psicoterapêuticos mediados por computador em resposta à crescente demanda para a oferta de serviços àqueles que não poderiam frequentar a modalidade presencial, como emigrados, viajantes, moradores de áreas rurais e pessoas com dificuldade de locomoção. Para que tal atendimento ocorresse, era exigido o cadastramento do profissional junto ao Conselho Federal de Psicologia (DONNAMARIA; TERZIS, 2011). Novas resoluções foram expedidas nos anos de 2012 e 2018, contudo, a mais atual é a de n 4, publicada em 26 de março de 2020. Esta resolução acelerou o cadastro de psicólogos no sistema e-Psi e os conseguintes atendimentos realizados no ambiente digital, conforme conduta ética preconizada nesta resolução. Na 
sequência apresentam-se os procedimentos e resultados dos grupos reflexivos e de apoio ao luto.

\section{PROCEDIMENTOS METODOLÓGICOS E RESULTADOS DOS GRUPOS REFLEXIVOS E DE APOIO AO LUTO}

Os grupos reflexivos e de apoio ao luto estão ancorado na metodologia dos grupos reflexivos de gênero do Instituto Noos - São Paulo e, por isso, três procedimentos metodológicos são utilizados: constituição do grupo; facilitação dos encontros reflexivos e avaliação final (BEIRAS e BRONZ, 2016). A primeira etapa da constituição do grupo foi divulgar o suporte psicológico ao luto à comunidade interna e externa à Universidade Federal de Santa Catarina (UFSC). Esta divulgação ocorreu no portal de notícias da UFSC e através de folhetos e banners espalhados em pontos estratégicos da universidade, bem como postos de saúde, hospitais e serviços de assistência social. No contexto da pandemia, informações sobre este suporte ao luto foram divulgadas no perfil da rede social virtual do Laboratório de Processos Psicossociais e Clínicos no Luto, ao qual também se encontram informações para a referida atividade grupal (Instagram LAPPSILu-Ufsc).

Os materiais de divulgação utilizados orientavam as pessoas enlutadas a encaminhar uma mensagem ao endereço eletrônico institucional do LAPPSILu (lappsilu@gmail.com.) referindo interesse de participar das atividades de apoio ao luto. Outra forma de contato com o projeto ocorreu por meio de encaminhamentos realizados pelos profissionais e estagiários do próprio Serviço de Atenção Psicológica da UFSC e hospitais da região de Florianópolis. Sendo assim, um amplo espectro de pessoas buscaram informações sobre o atendimento ao luto.

A fim de conhecer quais eram as demandas das pessoas interessadas, agendaram-se entrevistas individuais de acolhimento psicológico. As entrevistas realizadas no período de 2017 a 2019 ocorreram nas dependências do Serviço de Atenção Psicológica da UFSC. Por sua vez, as entrevistas com as pessoas que perderam um ente querido devido às complicações da Covid-19, e que foram realizadas em agosto de 2020, ocorreram por meio da plataforma 


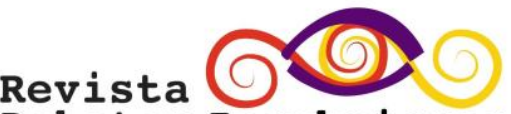 \\ Debates Insubmissos}

virtual Zoom. Em ambas as situações de entrevista o objetivo foi acolher a pessoa que buscou o suporte psicológico e conhecer se a demanda dela estava relacionada diretamente ou não a um processo de luto. Sendo assim, em alguns casos, a entrevista se estendeu para além de um encontro, tendo em vista o relato de várias demandas de saúde mental e que necessitavam de uma avaliação e encaminhamento urgente para outros serviços de saúde.

A entrevista de acolhimento psicológico foi realizada por meio de um roteiro construído a partir de outros questionários (FRANCO; TINOCO; MAZORRA, 2002; SOUZA; MOURA; PEDROSO, 2010). O uso desse roteiro serviu para orientar os extensionistas entrevistadores a realizar a avaliação e compreensão das reações de luto, os fatores de risco para complicações no luto e os fatores de proteção, tendo em vista os recursos pessoais e sociais de cada pessoa enlutada. Por meio desse roteiro, também se buscou identificar se o grupo de apoio ao luto era compatível com a demanda de cada pessoa.

Foram entrevistadas 78 pessoas, sendo que 65 delas apresentavam demandas de apoio diretamente relacionadas ao luto e 13 buscavam apenas a psicoterapia pessoal voltada para o enfrentamento de outros estressores e que não estavam relacionados ao luto ${ }^{3}$. A maioria das entrevistas de acolhimento realizadas com mulheres (69). A faixa etária das pessoas que mais procuraram o suporte psicológico ao luto ficou entre 30 e 40 anos, sendo que quatro crianças e dois adolescentes também foram entrevistados. Em relação a cidade de origem, a maioria das pessoas foi oriunda de cidades próximas à Florianópolis, mas houve também a procura de apoio por pessoas de outros estados brasileiros, sobretudo, quando foi divulgado que o atendimento seria realizado de forma online. Destaca-se que vários estudantes da UFSC também buscaram o suporte ao luto, bem como dois professores e um servidor técnico administrativo.

A constituição dos grupos reflexivos de apoio ao luto foi norteada pelo critério fatores de risco e vulnerabilidade para complicações no luto, tendo em vista o tipo de perda vivida, a

\footnotetext{
${ }^{3}$ Dificuldades de relacionamentos afetivos, escolha profissional, imigração, violência sexual, entre outros. Dessa forma, gerou-se a necessidade de encaminhamentos a locais condizentes com sua demanda, como o ambulatório de crise e intercultural do serviço de atenção psicológico da UFSC, ou ainda outros serviços-escolas de Psicologia, clínicas-sociais da cidade de Florianópolis, postos de saúde ou outros.
} 


\section{Revista \\ Debates Insubmissos}

intensidade e persistência das reações de luto. Sendo assim, do total de 65 pessoas interessadas em participar de alguma atividade de apoio ao luto, somente 50 pessoas estavam aptas para serem inseridas no grupo de apoio ${ }^{4}$. Houve também 15 pessoas que relataram processos de luto com complicações ${ }^{5}$ amplas e que exigiam outra estratégia interventiva, de modo que foram encaminhadas para a psicoterapia de luto ou para serviços de psiquiatria mais próximos à sua residência.

Foram constituídos e facilitados cinco grupos presenciais de outubro de 2017 a julho de 2019, sendo que um total de 43 pessoas participou de pelo menos um grupo com duração de oito encontros. De agosto a dezembro de 2020, sete pessoas participaram de um Gral realizado na plataforma virtual Zoom e que totalizou 10 encontros. Os seis grupos foram facilitados por extensionistas facilitadores e observadores bem como contou com participação de um profissional de Psicologia.

Todos os 50 enlutados que participaram de um dos seis grupos vivenciaram a construção do acordo de convivência, com a definição de algumas regras que serviam para mediar o comportamento dos participantes como, por exemplo, as formas de comunicação em caso de falta, atrasos e quanto à participação de novos integrantes após o início do processo grupal. Após esta etapa, era construída a agenda grupal com os temas que nortearam as conversações grupais. Destaca-se que a construção desta agenda esteve diretamente relacionada às perguntas disparadoras de conversa (condicionais e conversacionais) e que ampliavam as conversações entre os participantes do grupo, sendo que elas eram feitas por

\footnotetext{
${ }^{4}$ Isto quer dizer que estas pessoas apresentavam reações de anseio pela volta da pessoa falecida, falta de espaço social para falar da perda, rede de apoio social pouco empática, conflito com crenças religiosas, sentimento de vazio, culpa e raiva, vontade de fazer mudança na vida, dificuldade de comunicação familiar e sintomas físicos relacionado a perda (insônia, distúrbios gastrointestinais, desatenção, fraqueza muscular, entre outros).

${ }^{5}$ Intenso sentimento de anseio e sofrimento pela volta da pessoa que morreu, persistências das reações de luto ao longo do tempo, ideação suicida, abuso de drogas e álcool, isolamento, culpa, raiva, medo do futuro, não aceitação da morte, sentimentos depressivos, despersonalização, pensamentos recorrentes sobre a pessoa que morreu, pesadelos, dor crônica; medo de novas perdas e sentimentos de incapacidade. Observou-se também que alguns participantes apresentavam outros estressores coincidindo com a perda atual, por exemplo: dificuldades econômicas, sobrecarga de responsabilidades na família ou graves conflitos com familiares após a perda, por exemplo, violência e abuso de drogas.
} 


\section{Revista \\ Debates Insubmissos}

todos os participantes do encontro e não só pelos facilitadores (ESTEVES DE VASCONCELLOS, 2010).

As perguntas condicionais se referiam a busca por conhecer a história pessoal de cada participante e suas vivências de luto, o vínculo que tinham com a pessoa que morreu, a sua família e cultura, as formas específicas de cuidar e conviver com o luto, as vulnerabilidades da pandemia pelo novo coronavírus, entre outras. Além disso, à medida que os participantes iam confiando uns nos outros e nos facilitadores - contando, ouvindo, pensando e perguntando sobre as histórias partilhadas no coletivo - surgiam as perguntas conversacionais, especialmente, no momento da síntese do encontro.

Estas perguntas implicavam a adoção de uma postura reflexiva, tanto por parte dos facilitadores quanto dos participantes, no sentido de se compreender a complexidade das narrativas de luto pessoais e coletivas tecidas em cada encontro grupal. Por exemplo, perguntas conversacionais dão visibilidade aos vários tipos de luto e a dificuldade de expressá-los. Ao final da síntese do encontro, também são realizadas as despedidas por meio de recursos da música, frase, palavra, filme, séries da televisão, cartilhas, livros, biografias sobre luto e documentários.

Todos os encontros dos seis Gral relatados e registrados em formulário próprio. Estes registros foram partilhados em encontros de supervisão, com vistas a elaborar e proceder à análise qualitativa de acordo com os procedimentos da Grounded Theory (STRAUSS; CORBIN, 2008). Nessa análise, inicialmente, identificaram-se os temas presentes nos relatos dos distintos momentos do grupo, acordo de convivência, construção agenda grupal e síntese/despedida do encontro (codificação aberta). Em seguida, sublinharam-se os temas comuns e distintos dos referidos momentos (codificação axial). Desse processo, constituíramse cinco categorias temáticas: 1) necessidades de apoio ao luto; 2) modos de expressão do luto; 3) impactos do luto na saúde mental e na família; 4) vivências interseccionais no luto; e 5) cuidar e conviver com as perdas.

O tema necessidades de apoio ao luto foi referido pelos participantes quando narraram que não se sentiam acolhidos em seus contextos relacionais, como a família, amigos ou 
trabalho, tendo em vista os diferentes tipos de dores no luto. Por exemplo, os participantes dos cinco Gral realizados antes da pandemia (2017 a 2019) relataram a necessidade de serem acolhidos na dor do deixar partir e que era relativa à ansiedade de separação, choro, isolamento, fraqueza muscular etc. Outros participantes, por sua vez, se referiram a necessidade de acolhimento quanto a dor do dizer olá novamente - manter conversas, fotos, pequenos objetos ou cartas da pessoa falecida no ambiente familiar - e que nem sempre era vista por pessoas da família como um comportamento saudável. E, também, havia participantes que destacaram os conflitos quanto à necessidade de retomada da vida sem o ente querido - a dor do seguir em frente -, de modo que assinalavam as consequências da perda na vida pessoal, financeira, destacando, também, os conflitos familiares.

No Gral realizado no ano de 2020 esteve presente a necessidade de apoio para lidar com as dores do deixar partir e do dizer olá novamente. Os participantes buscavam respostas e sentidos para morte por Covid-19, bem como visavam reconstruir memórias sobre a pessoa que havia morrido e formas de se conectar simbolicamente com as lembranças e significados da relação, tendo em vista a falta dos rituais funerários tradicionais e precariedade da participação de familiares e amigos na memorialização da pessoa que faleceu.

Outra temática dos grupos foi o modo de expressão do luto por meio de rituais coletivos a partir de crenças religiosas e comportamentos de luto específicos. Em geral, os participantes dos grupos realizados antes da pandemia relataram como muito dolorosa a passagem pelo ritual do velório, e que implicou a contemplação do corpo no caixão, mas consideravam este momento importante para concretizar a realidade da perda. Por sua vez, o modo de expressão do luto foi relatado pelos participantes enlutados pela Covid-19 como sendo precário, tendo em vista a rapidez dos velórios e enterros. Por outro lado, a expressão do luto coletivo foi preponderante por meio do uso de plataformas virtuais e validação do luto de outras pessoas enlutadas pela Covid-19.

A temática do impacto do luto na saúde mental ocorreu por meio de conversações sobre luto e doença mental ou ainda luto e fracasso existencial. Às vezes, alguns participantes buscavam influenciar as demais pessoas do grupo sobre o valor das suas crenças para lidar 
com reações de ansiedade, depressão, raiva ou culpa. Outro tema discutido foi o impacto do luto na família tendo em vista que o modo de morrer do ente querido foi repentino, bem como as pessoas falecidas serem jovens.

O tema vivências interseccionais no luto foi observado em todos os grupos realizados, especialmente quando os participantes relataram como as questões de sexualidade, classe, raça e gênero influenciou o auto reconhecimento das suas necessidades de enlutamento bem como validação destas pela sociedade. Neste sentido, a dificuldade ao expressar o sofrimento esteve presente no relato de participantes pela perda de um animal de estimação, homicídio de um filho, perda de um familiar pela Covid-19, perda do cônjuge e viuvez lésbica, perdas pelo abuso de drogas, afastamento da família e morte de um filho por suicídio, perda gestacional, lutos cronificados depois de um longo tempo de luto. E, por fim, a temática cuidar e conviver com as perdas se relaciona com as ações de cuidado de si e retomada da vida pessoal pelos participantes, como voltar ao trabalho, meditar, buscar uma religião ou ainda envolver-se com algum ritual personalizado de autocuidado, entre outras.

Na sequência, discutem-se as cinco temáticas recorrentes nos grupos reflexivos de apoio ao luto a luz dos desafios à promoção da saúde, tendo em vista o princípio da interseccionalidades (MENDÉZ, 2012) e de outros conceitos, como o direito ao luto público e coletivo (BUTLER, 2018), a perspectiva construcionista social sobre o luto (LUNA, 2019), ética relacional (GERGEN, 2016) e os princípios terapêuticos grupais (YALOM; LESZCZ, 2006).

\section{ANÁLISE DOS GRUPOS REFLEXIVOS E DE APOIO AO LUTO}

O termo interseccionalidade foi sistematizado pela intelectual afro-estadunidense Kimberlé Crenshaw em 1989 (AKOTIRENE, 2019). Surgiu a partir das críticas realizadas pelo feminismo negro ao sistema de opressões estruturais do racismo, do capitalismo, do sexismo, do cisheteropatriarcado, produtores das avenidas identitárias que perpassam os sujeitos e muitas vezes silenciam a expressão da dor, do sofrimento e do pesar. Nesse sentido, 
compreendemos o campo das interseccionalidades como indissociável da discussão sobre a promoção da saúde no luto. Para tanto, foi muito importante olharmos para as condições de vida e vivências singulares externalizadas pela pessoa enlutada no contexto grupal como sendo produto de processos reflexivos e comunitários, posições e compreensões prévias acerca de como as questões de raça, gênero, sexualidade, classe social, religião atravessam as suas vivências de luto.

Sendo assim, vivências interseccionais no luto estiveram presentes nas relações grupais do Gral na medida em que se ligavam às narrativas pessoais de luto de cada participante quanto às normas binárias de gênero internalizadas, que significa validar como natural e correto um modo feminino ou masculino de enlutar-se. Deste modo, observou-se empatia dos participantes às respostas de luto vistas como masculinas - quando relacionadas às vivências instrumentais, voltadas a pensamentos e ações - ou ainda as respostas femininas de luto relacionadas às vivências intuitivas por meio das quais as mulheres externalizam suas emoções (DOKA; MARTIN, 2010). Sendo assim, um desafio na promoção da saúde no luto foi dar visibilidade e desconstruir com os participantes do Gral os estereótipos e maneiras unívocas das pessoas em ter empatia e validar as vivências de luto pré-definidas nos corpos, nos comportamentos, dramatizações e performances a partir das normas binárias de gênero.

Outro desafio aportado ao Gral foi identificar com os participantes as posições de privilégio ou de vulnerabilidades sociais ocupadas por sujeitos enlutados e que tornam algumas vivências visíveis ou invisíveis para si e para a sociedade. Ou seja, o fracasso de empatia (ATTIG, 2004) presente nas interações familiares ou outras relações do cotidiano da pessoa enlutada LGBT $+{ }^{6}$ e não branca. Nesse sentido, foi importante atentar para os impactos do estresse social minoritário (LONGOBARDI e BADENES-RIBERA, 2017; LEFEVOR et al, 2019) no luto e como os fatores socioculturais de negação de direitos civis, discriminação com base na orientação sexual e cor de pele, crimes de ódio, vivências de homofobia em

${ }^{6}$ Lésbicas, Gays, Bissexuais, Travestis e Transexuais e demais performances divergentes da norma heterossexual representadas pelo sinal +. Sigla padronizada na $1^{\circ}$ Conferência Nacional LGBT no ano de 2008 em Brasília. 
relações familiares, estigma da homofobia e ocultação da identidade sexual podem agravar a não visibilidade e estigmatização do luto para quem é LGBT+ (LEHNEN, 2016; ARIMA; FREITAS, 2017) e não branco (TAVARES; KURATANI, 2019).

As autoras Huning e Scisleski (2018) também ajudam a compreender como as vulnerabilidades sociais ecoam em questões que excedem os participantes do Gral, como os fatores de proporções históricas que compõem a esfera social, comprometendo a garantia de direitos desses cidadãos e, também, gerando desvantagens e ausência de oportunidades. Nesta ótica, foi fundamental compreender as condições de vida dos participantes que são atravessados pelas vulnerabilidades sociais, sobretudo, no que se refere às histórias pessoais sobre a perda vivida e à falta do apoio financeiro, psicológico, afetivo e social.

No que se refere às vulnerabilidades sociais a que estavam expostos os participantes do Gral durante a pandemia da Covid-19, visualiza-se também perdas pessoais e coletivas quanto aos meios de subsistência e que afligiu o bem-estar de todos os participantes do grupo. Também se observou os contornos trágicos dos discursos conflitantes emitidos por governos que se opõem às medidas preventivas contra a transmissão do novo coronavírus Sars-coV-2, a falta de preparo e investimento por parte dos governos nos sistemas de saúde e demais políticas públicas para lidarem com as consequências negativas da pandemia, as quais acentuaram as vulnerabilidades sociais já existentes em nossa sociedade pré-pandemia, bem como dificultou a vida das pessoas enlutadas no que tange ao processo elaborativo de luto em torno da dor do seguir em frente sem o ente querido.

No Gral realizado no contexto online verificam-se algumas limitações no campo visual e corporal, exigindo dos facilitadores maior atenção às expressões faciais, respiração, pausas e olhares durante os encontros do grupo. Além disso, salienta-se que a utilização dos serviços online exige recursos de internet que muitos brasileiros não têm acesso (SCHMIDT et al, 2020), devido às barreiras sociais existentes no país. Sendo feita tal reflexão, é pertinente, então, questionar o dever do Estado em garantir o direito ao acesso à internet em um cenário de pandemia, onde se incentiva e oportuniza cada vez mais a qualidade de vida por meios virtuais. 
Por sua vez, foi saliente a motivação dos participantes que perderam um ente querido pela Covid-19 ao participar dos encontros grupais, tendo em vista o isolamento social bem como a precariedade nos rituais fúnebres realizados e que restringiram a duração e o número de pessoas próximas ao enlutado (DANTAS et al, 2020). Ademais, também foi referido por esses enlutados que o contexto virtual os sobrecarregou com notícias irreais, em que mídias, com deturpação das legendas e informações sobre a gravidade da pandemia, inspiravam discórdia e violência entre a população.

Nesse sentido, a visão de Sontag (2003, p. 16) nos traz a reflexão sobre "as inúmeras possibilidades oferecidas pela vida moderna de ver - à distância, por meio da fotografia - a dor de outras pessoas" e o quanto essa imersão às notícias constantes, em cenário de conflito político-ideológico, proporciona identificação ou aversão ao seu conteúdo, influenciando a perda da empatia, o desrespeito aos enlutados por entes queridos, além de aumentar ou reduzir o engajamento com o compromisso social em momentos de crise. Nesse caso, as cartilhas de orientações para os rituais de luto são vistas como dispositivos de promoção à saúde uma vez que instrumentalizam os enlutados pela Covid-19 no acesso às informações, à educação e à expressão do luto de forma segura (COGO et al, 2020).

Observa-se que nos seis grupos realizados foi possível construir espaços de fala e escuta que auxiliaram os participantes a expressar o seu luto publicamente. Isto significa fomentar a ética relacional (GERGEN, 2016), ou seja, uma prática responsiva e empática entre os participantes para que se sintam apoiados para externalizar as três dores ou processos elaborativos de luto como: processar e expressar as emoções e sentimentos de luto (a dor do deixar partir); restaurar a identidade e reorganizar a vida (a dor do seguir em frente); e preservar as memórias e as lembranças dos melhores momentos de vida com a pessoa ou situação que foi perdida (a dor do dizer olá novamente) (LUNA, 2019).

Nesse sentido, destaca-se que o suporte grupal aos processos elaborativos de luto foi outro desafio da promoção à saúde nos seis Gral, sendo que este pode ser visto mediante o fomento de relações de confiança, compartilhamento das vivências interseccionais no luto, pela troca de informações sobre os recursos de cuidado de si e retomada de vida cotidiana, 
construção de sentidos da vida e da morte, bem como pela aprendizagem mútua decorrente da percepção de alguns benefícios no enfrentamento de uma perda (YALOM; LESZCZ, 2006).

\section{CONSIDERAÇÕES FINAIS}

Ao facilitarem-se grupos reflexivos e de apoio ao luto (Gral) no contexto do serviçoescola de Psicologia e considerando também o uso das tecnologias da informação e da comunicação durante o período da pandemia pelo novo coronavírus Sars-coV-2, um dos desafios à promoção da saúde no luto foi compreender e apoiar a necessidade de enlutamento dos participantes, tendo em vista que muitos lutos eram invisibilizados em outros contextos relacionais. Outro desafio na promoção à saúde foi a construção da postura empática entre participantes e facilitadores para narrar e coproduzir com o outro e no coletivo os sentidos do impacto do luto na saúde mental e na família, as vivências interseccionais e o cuidar e conviver com as perdas. Considera-se que os dois desafios apontados são fundamentais para fomentar processos elaborativos de luto relacionados a três tipos de dores - deixar partir, seguir em frente e dizer olá novamente. Acolher estas dores implica dar visibilidade a quem morreu, quem é o enlutado, onde ele vive e qual é a sua cultura, seu gênero, sexualidade, raça, etnia e classe social.

Deste modo, tanto os grupos reflexivos e de apoio ao luto realizados antes da pandemia pelo novo coronavírus Sars-coV-2 quanto o realizado durante a pandemia favoreceram são grupos de promoção a saúde pois estavam envolvidos com a construção de espaços de falas e escuta, empatia, sociabilidade, confiança e aceitação dos processos elaborativos de luto. Nesse sentido, é relevante destacar que na avaliação final dos seis Gral os participantes relataram vivências de altruísmo e universalidade, pois puderam falar e ser escutados, bem como perceber que o Gral faz parte de suas vidas cotidianas, principalmente porque foi por meio dos encontros grupais que os participantes formaram grupos de WhatsApp. Este aspecto aponta que o Gral possibilitou espaços de sociabilidade e relações de apoio para além dos encontros reflexivos. Considera-se que este é um dos aspectos mais centrais e desafiadores da promoção da saúde no Gral: o fortalecimento dos sujeitos enlutados 
pela coconstrução de seus recursos de enfrentamento e amparo do coletivo e redes sociais de apoio que fez sentido a eles.

\section{REFERÊNCIAS}

AKOTIRENE, Carla. Interseccionalidade. São Paulo: Editora Jandaíra, 2019, 152p. (Série Feminismos Plurais).

ARIMA, Ana Carolina; FREITAS, Joanneliese de Lucas. O Luto Velado: A Experiência de Viúvas Lésbicas em uma Perspectiva Fenomenológico-Existencial. Trends in Psychology, Curitiba, n. 4, p. 1467-1482, oct-dez. 2017.

ATTIG, Thomas. Disenfranchised grief revisited: discounting hope and love. Journal of Death and Dying, Detroit, n. 3, p 197-215, nov. 2004.

BEIRAS, Adriano; BRONZ, Alan. Metodologia de grupos reflexivos de gênero. Rio de Janeiro: Instituto Noos, 2016, 45p.

BRASIL. Constituição. Constituição da República Federativa do Brasil. Brasília, DF, Senado Federal, 1988.

BRASIL. Resolução no 41, de 31 de outubro de 2018. Dispõe sobre as diretrizes para a organização dos cuidados paliativos, à luz dos cuidados continuados integrados, no âmbito Sistema Único de Saúde (SUS). Diário Oficial da União, Brasília, DF, v. 01, n. 225, 2018.

BUSS, Paulo Marchiori. Uma introdução ao conceito de promoção da saúde. In:

CZERESNIA, Dina e DE FREITAS, Carlos Machado (Org.). Promoção da Saúde: conceitos, reflexões e tendências. Rio de Janeiro: Editora Fiocruz, 2003. p. 15-38.

BUTLER, Judith. Quadros de guerra: quando a vida é passível de luto?. Rio de Janeiro: Civilização Brasileira, 2018, 288p.

COGO, Adriana Silveira et al. Saúde Mental e Atenção Psicossocial na Pandemia COVID-19: Processo de Luto no Contexto da COVID-19. Rio de Janeiro: Fiocruz/CEPEDES, 2020, 10p.

CONSELHO FEDERAL DE PSICOLOGIA. Resolução nº 4/2020. Dispõe sobre regulamentação de serviços psicológicos prestados por meio de Tecnologia da Informação e da Comunicação durante a pandemia do COVID-19. Brasília, 2021, 2 p. CONSELHO FEDERAL DE PSICOLOGIA. Resolução CFP n ${ }^{\circ}$ 012/2005. Regulamenta o atendimento psicoterapêutico e outros serviços psicológicos mediados pelo computador e revoga a Resolução CFP n⿳0 003/2000. Brasília, 2005, 5 p. 
DONNAMARIA, Carla Pontes; TERZIS, Antonios. Experimentando o dispositivo terapêutico de grupo via internet: primeiras considerações de manejo e desafios éticos. Revista da SPAGESP, São Paulo, n. 2, p. 17-26, dez. 2011.

DANTAS, Clarissa de Rosalmeida et al. O luto nos tempos da COVID-19: desafios do cuidado durante a pandemia. Rev. Latinoam. Psicopat. Fund., São Paulo, n. 3, p 509-533, jul-set. 2020.

DAVEL, Alzira da Penha Costa; SILVA, Daniela Reis e. O processo de luto no contexto do APIES: aproximando as narrativas. Pensando família, Porto Alegre, n. 1, p.107-123, jun. 2014.

DOKA, Kenneth J; MARTIN, Terry L. Grieving beyond gender: understanding the way Men and Women Mourn. New York: Routledge, 2010, 264p.

ESTEVES DE VASCONCELLOS, Maria José. O uso de perguntas como recurso para desencadear mudanças sistêmicas: articulando os múltiplos rótulos utilizados para diferentes formas de perguntar. In: AUN, Juliana Gontijo; ESTEVES de VASCONCELLOS, Maria José e COELHO, Sonia Vieira (Orgs.). Desenvolvendo práticas com a metodologia de atendimento sistêmico. Belo Horizonte: Ophicina de Arte \& Prosa, 2010. p. 186-209.

FRANCO, Maria Helena Pereira; MAZORRA, Luciana; TINOCO, Valéria. Questionário sobre fatores de risco para luto complicado. In: FRANCO, Maria Helena Pereira (Org.).

Estudos avançados sobre o luto. São Paulo: Editora Livro Pleno, 2002. p. 62-67.

GUILLÉN, Elena Guillén; MONTAÑO, José Gordillo; GORDILLO, Dolores Gordillo. El grupo me ayudó a no estancarme. El avance en el proceso de duelo. International Journal of Developmental and Educational Psychology INFAD, Badojóz, n. 1, p. 469-476, mar. 2015.

GERGEN, Kenneth J. Rumo a uma ética relacional para a prática terapêutica. Nova Perspectiva Sistêmica, São Paulo, n. 56, p. 11-21, dez. 2016.

HUNING, Simone M.; SCISLESKI, Andrea. A noção de vulnerabilidade da Política Nacional de Assistência Social. In: CORDEIRO, Mariana Prioli; SVARTMAN, Bernardo e SOUZA, Laura Vilela (Orgs.). Psicologia na Assistência Social: um campo de saberes e práticas. São Paulo: Instituto de Psicologia, 2018. p. 133-144.

KOVÁCS, Maria Julia. Desenvolvimento da Tanatologia: estudos sobre a morte e o morrer. Pandéia, Ribeirão Preto, n. 41, p. 457-468, set-dez. 2008.

LEFEVOR, G. Tyler et al. Health Disparities Between Genderqueer, Transgender, and Cisgender Individuals: An Extension of Minority Stress Theory. Journal of Counseling Psychology, Maryland, n. 4, p. 385-395, jul. 2019.

LEHNEN, Jeremy Lee. Mourning Love: amor, luto e direitos em "Requiem sertanejo". ProPosições, Campinas, n. 1, p 57-72, jan-abr. 2016. 
LONGOBARDI, Claudio; BADENES-RIBERA, Laura. Violência entre parceiros íntimos em relações do mesmo sexo e o papel dos estressores de minorias sexuais: uma revisão sistemática dos últimos 10 anos. Journal of Child Fam Stud., Estados Unidos, vol. 26, p 2039-2049, ago. 2017.

LUNA, Ivânia Jann. Narrativas de homens viúvos diante da experiência de luto conjugal. Nova Perspectiva Sistêmica, São Paulo, n. 64, p. 32-46, ago. 2019.

LUNA, Ivânia Jann. A implantação do cuidado profissional ao luto no contexto de uma universidade pública: desafios éticos e metodológicos. In: LUNA, Ivânia Jann (Org.) A quem confiar minha tristeza? Faces e perspectiva do cuidado ao luto. Curitiba: Brazil Publishing, 2020. p. 145-160.

MENDÉZ, Raquel Lucas Platero. La interseccionalidad como herramienta de estudio de la sexualidad. In: MENDÉZ, Raquel Lucas Platero (Org.). Intersecciones: cuerpos y sexualidades en la encrucijada. Barcelona: Ediciones Bellaterra, 2012. p. 15-74.

MORAES, Ivete Iara Gois; STOLZ, Sheila. A temática da morte na educação em e para os Direitos Humanos. In: BRAUNER, Maria Cláudia Crespo; PIERRE, Philippe (Orgs.).

Direitos Humanos, Saúde e Medicina: uma perspectiva internacional. Rio Grande: Ed. da FURG, 2013. p.133-161.

PASCOAL, Melissa. Trabalho em grupo com enlutados. Psicologia em Estudo, Maringá, n. 4, p. 725-729, dez. 2012.

PRIGERSON, Holly G.; VANDERWERKER, Lauren C.; MACIEJEWSKI, Paul K. A case for inclusion of prolonged grief disorder in DSM-V. In: STROEBE, Margaret S.; HANSSON, Robert O.; SCHUT, Henk; STROEBE, Wolfgang (Orgs.). Handbook of bereavement research and practice advanced in theory and intervention. Washington: American Psychological Association, 2008. p. 165-186.

REBELO, João Eduardo. Importância da entreajuda no apoio a pais em luto. Análise Psicológica, Lisboa, n. 4, p.373-380, 2005.

RUBIO, Andreza Viviane et al. O grupo de pais enlutados como proposta de cuidado ao luto familiar. Rev. Eletrônica SIMTEC. Campinas, n. 6, p. 156-156, out. 2016.

SANTOS, Gabriela Casellato Brown Ferreira. Intervenção do profissional de saúde mental em situações de perda e luto no Brasil. Revista M., São Paulo, n. 3, p. 116-137, fev. 2017. SANTOS, Luciane de Medeiros et al. Grupos de promoção à saúde no desenvolvimento da autonomia, condições de vida e saúde. Revista de Saúde Pública, São Paulo, n. 2, p. 346-352, abr. 2006. 
SCAVACINI, Karen; CORNEJO, Elis Regina; CESCON, Luciana França. Grupo de apoio para enlutados por suicídio. Revista M., São Paulo, n. 7, p. 201-214, set. 2019.

SCHMIDT, Beatriz et al. Impactos na Saúde Mental e Intervenções Psicológicas Diante da Pandemia do Novo Coronavírus (COVID-19). Revista Estudos de Psicologia, Campinas, n. 37, p. 1-13, abr. 2020.

SOARES, Larissa Gramazio et al. Mães de anjos: (re)vivenciando a morte do filho como estratégia de enfrentamento. Escola Anna Nery, Rio de Janeiro, n. 1,p. 1-9, fev-ago. 2020. SONTAG, Susan. Diante da dor dos outros. São Paulo: Companhia das Letras, 2003, 107p. SOUZA, Airle Miranda de; MOURA, Danielle do Socorro Castro; CORRÊA, Victor Augusto Cavaleiro. Implicações do pronto atendimento psicológico de emergência aos que vivenciam perdas significativas. Psicologia Ciência e Profissão, Brasília, n. 3, p. 534-543, fev. 2009.

SOUZA, Andréia Santiago Sobreira Santos; SANTOS, Franklin Santana. Histórias de morte e luto: um estudo socioantropológico da vivência da morte em um grupo operativo no CRAS. Revista de Psicologia, Fortaleza, n. 2, p. 50-58, mar. 2016.

SOUZA, Airle Miranda de; MOURA, Danielle do Socorro Castro; PEDROSO, Janari da Silva. Instrumento de avaliação do luto e suas funções terapêuticas: a experiência em um serviço de pronto atendimento ao enlutado. In: FRANCO, Maria Helena Pereira (Org.).

Formação e rompimento de vínculos: o dilema das perdas na atualidade. São Paulo: Summus, 2010. p. 123-144.

STRAUSS, Anselm; CORBIN, Juliet. Pesquisa Qualitativa: técnicas e procedimentos para o desenvolvimento de teoria fundamentada. Porto Alegre: Artmed, 2008, 283p.

TAVARES, Jeane Saskya Campos; KURATANI, Sayuri Miranda de Andrade. Manejo Clínico das Repercussões do Racismo entre Mulheres que se "Tornaram Negras". Psicologia Ciência e Profissão, Brasília, n.1, p. 13-18. out. 2019.

YALOM, Irvin D.; LESZCZ, Molyn. Psicoterapia de grupo: teoria e prática. Porto Alegre: Artmed, 2006, 528p.

WORLD HEALTH ORGANIZATION. Conselhos sobre a doença coronavírus (COVID19) para o público, Genebra, 2021.

Submetido: $31 / 05 / 2021$

Aprovado: 26/08/2021 